\title{
A NEW SPECIES OF POLYCELIS (PLATYHELMINTHES, TRICLADIDA, PLANARIIDAE) FROM CHINA
}

\author{
Zi-Mei Dong, Guang-Wen Chen*, He-Cai Zhang and De-Zeng Liu \\ College of Life Science, Henan Normal University \\ Jianshe Road No.46, Xinxiang 453007, Henan, China; E-mail: chengw0183@sina.com
}

In this paper, a new species of Polycelis of the family Planariidae from China is described. Mature individuals have 80-140 eyespots; the testes are well-developed and most of them occupy the entire dorso-ventral space; the penis is a long cone with well-developed musculature; the boundary between the penis bulb and penis papilla is vague and the bulbar cavity is not observed; the bursal canal is surrounded by a well-developed coat of circular muscles, and a thin layer of longitudinal muscles. The karyotype shows a diploid complement of 38 chromosomes, with the formula $2 n=38=24 m+14 \mathrm{sm}$.

Key words: Platyhelminthes, Tricladida, Polycelis, new species, China.

\section{INTRODUCTION}

The genus Polycelis Ehrenberg, 1831 belongs to the family Planariidae Stimpson, 1857 (Tricladida) and is not homogeneous. In general, the genus Polycelis is characterized by the features of the genital anatomy and histology, and they can be divided into two groups: the genera Polycelis Ehrenberg, 1831 and Seidlia Zabusov, 1911; the former includes two subgenera: Polycelis Ehrenberg, 1831 and Ijimia Bergedal, 1890 (Kenk 1953, Kawakatsu \& Mitchell 1998). To date, there are about 30-40 species of Polycelis sensu lato and they are distributed in Europe, Central Asia, the Far East, and the United States, of which 8 species occur in China (Hyman 1934, Liv 1993, 1994, 1995, 1996, CHeN et al. 2001 a, b), they are as follows: Polycelis koslowi Zabusov, 1911, P. nyingchica Liu, 1994, P. xigazensis Liu, 1994, P. sinensis Liu, 1995, P. Ihunzhubica Liu, 1995, P. wutaishanica Liu, 1996, P. jinglensis Liu, 1996 and P. jingyuanica Liu, 1996. In this study, we describe a new species of Polycelis from Shanxi Province, China, which was identified on the basis of morphological, histological and karyological data.

\section{MATERIAL AND METHODS}

Specimens were directly collected under stones with a brush from a small spring (the source of the spring is called Chengqianggen, while the midstream of the spring is called Renbi rut) in the Taihang Mountains, Yangcheng County, Shanxi Province, China. After the planarians were collected and washed by the clear spring water, they were cultured in 
autoclaved tap water at approximately $13^{\circ} \mathrm{C}$ and fed once a week with fresh fish spleen. The worms were starved for at least one week before being used for karyotyping and morphological studies. Images of planarian morphology were obtained by using a Leica digital camera attached to a compound stereo-microscope (M165C, Germany).

Histological sections were prepared as described previously (CHEN et al. 2005). In brief, the worms were killed with $1 \%$ nitric acid. After fixation in Bouin's fluid, the animals were rinsed with $70 \%$ ethanol, and subsequently, dehydrated in ascending series of ethanol solutions, cleared in xylene, and embedded in synthetic paraffin. Serial sections were made at intervals of $8 \mu \mathrm{m}$ and were stained with hematoxylin and eosin. Images were acquired by with a Leica digital camera attached to a compound microscope (DMLB, Germany).

All specimens examined have been deposited in the Zoological Museum of the College of Life Science of Henan Normal University, Xinxiang, China. Living specimens were cultured in our laboratory.

Chromosomal preparation was performed according to the protocol described in CHen et al. (2008). In brief, animals $12-17 \mathrm{~mm}$ in length and $2.0-3.0 \mathrm{~mm}$ in width were used. The worms, collected from the Chengqianggen, were cut transversally into three pieces and cultured in distilled water for three days. The regenerative blastemas were treated with a $0.02 \%$ colchicine solution at $4^{\circ} \mathrm{C}$ for $2.5-3.5$ hours and then placed in $0.1 \% \mathrm{KCl}$ hypotonic solution at $13^{\circ} \mathrm{C}$ for approximately $1.5-3.5$ hours. Afterwards, they were washed with deionized water and then fixed on a slide for about 30 seconds in each of the following solutions: fixative fluid I (glacial acetic acid: absolute alcohol: deionized water in the ratios 3:3:4), fixative fluid II (glacial acetic acid: absolute alcohol as in 1:1 proportion) and fixative fluid III (glacial acetic acid). Then, the dispersed cells were dried at room temperature for 24 hours, and stained with a $0.5 \%$ Giemsa solution for 10-15 minutes. The mitotic metaphase chromosomes of the regenerative blastema cells were observed and photographed under a transmission microscope (BX40, Olympus) equipped with a digital camera (Olympus DP70). The metaphase plates from five well-spread sets of chromosomes of different individuals were used for karyotype analysis, while karyotype parameter measurements were carried out as described previously (CHEN et al. 2008). Chromosomes were classified on the criteria proposed by Levan et al. (1964).

Abbreviations used in the figures - a: auricle; bc: bursal canal; ca: common atrium; cb: copulatory bursa; $\mathrm{cm}$ : circular muscle; co: common ovovitelline duct; cor: copulatory organ; e: eye; ed: ejaculatory duct; gp: gonopore; i: intestine; lm: longitudinal muscle; m: mouth; ma: male atrium; o: ovary; od: ovovitelline duct; p: penis; pb: penis bulb; ph: pharynx; pp: penis papilla; eg: eosinophilic gland; sd: sperm duct; spv: spermiducal vesicle; t: testis.

\section{RESULTS}

\section{Polycelis yangchengensis sp. $n$.}

(Figs 1-8)

Material examined - Holotype: CQ1, one set of sagittal sections on 5 slides, Chengqianggen of Taihang Mountains in Yangcheng County, Shanxi Province, 05 July 2002, alt. $1658 \mathrm{~m}$ at $112^{\circ} 09.133^{\prime} \mathrm{E}, 35^{\circ} 16.398^{\prime} \mathrm{N}$; water temperature $5.5-10.5^{\circ} \mathrm{C}, \mathrm{pH} 6.0$.

Paratypes: CQ2, Chengqianggen of Taihang Mountains in Yangcheng County, Shanxi Province, 05 July 2002, sagittal sections on 8 slides; CQ3-4, ibid, transverse sections on 9, and 10 slides, respectively; CQ5-6, ibid, horizontal sections on 6 , and 8 slides respectively. 
Other material: RB1-2, Renbi Rut of Taihang Mountains in Yangcheng County, Shanxi Province, 06 July 2002 , alt. $1371 \mathrm{~m}$ at $112^{\circ} 08.424^{\prime} \mathrm{E}, 35^{\circ} 16.251^{\prime} \mathrm{N}$; water temperature $5.5-10.5^{\circ} \mathrm{C}$, pH 6.0, sagittal sections on 9, and 8 slides; RB3, 4, 5, ibid, horizontal sections on 6, 8, and 9 slides respectively; RB6-7, ibid, transverse sections on 15 , and 10 slides respectively.

Diagnosis - Prepharyngeal testes, filling most of the dorso-ventral space extending from the level of the ovaries. Penis a long cone with well-developed musculature. Boundary between penis bulb and penis papilla vague. Bulbar cavity not observed. Two sperm ducts entering to the ejaculatory duct separately at the $1 / 3$ rd $-1 / 4$ th as long as the penis near the distal portion. Bursal canal with an inner well-developed coat of circular muscles and a thin outer longitudinal one. Chromosome complement consisting of a diploid number of 38 chromosomes, with karyotype formula $2 \mathrm{n}=38=24 \mathrm{~m}+14 \mathrm{sm}$.

Etymology - This species is named after the geographic location (Yangcheng county) where its type specimen was found.

External characters - The general appearance of the living specimens of this species is shown in Figs 1A, B. The living sexually mature individuals measure up to $12-17 \mathrm{~mm}$ in length and 1.5-2.5 mm in width. In life, the head has a broad, subtriangular form and frontal body margin provided with a median bulge, with a pair of rather pointed auricles extending anterolaterally. Posteriorly to the auricles, the body is slightly narrower and then gradually widens again. After this, the body remains about the same width until the

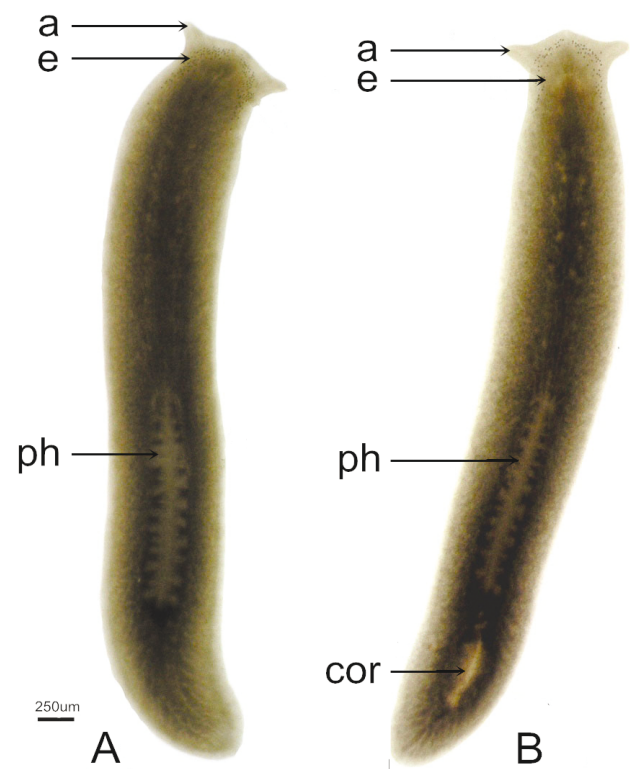

Fig. 1. Photographs of Polycelis yangchengensis, live specimens: $\mathrm{A}=$ sexually immature individual, $\mathrm{B}=$ sexually mature individual region of the copulatory complex. Posteriorly to the copulatory complex, the body gradually becomes narrower to end in a blunt tail (Figs 1A, B).

The color of living specimens is tawny to dark chocolate-brown of the dorsal side, while, the ventral side is slightly lighter than that of the dorsal body surface. The color of fixed specimens is gray white. In living fully sexually mature specimens, the copulatory bursa, the penis and a part of spermiducal vesicle can be seen from the ventral side (Figs 1A, B).

The species possesses numerous small eyes arranged in two bands (80-140 in total) near the anterior and the lateral margins of the head. There are no eyes in the mid-dorsal part of the head. These ocular bands are widest at the level of the auricles and terminate some distance behind the auricles at the anterior one-fifth level of the prepharyngeal region. Within each band the small eyes are distributed irregularly (Figs 1A, B). 
The pharynx is inserted in the posterior half of the body. It is long and strongly musculature with a length nearly $1 / 3-1 / 4$ th as long as the body length and with a width of nearly $1 / 3$ rd of the body width. The mouth is located at the hind end of the middle $1 / 4$ th of the body. The genital pore is found in the midline at rather posterior level of the middle of the postpharyngeal region, the ratio of the distances between mouth to gonopore and genital pore to the end of the tail is $4: 3$ (Figs 1A, B).

Internal characters - The pharynx has a structure typical of the genus Polycelis in the family Planariidae, the musculature of the pharynx consists of two layers: outer epithelium of pharynx underlain by a layer of longitudinal muscles, followed by layer of circular muscles. A thick layer of circular muscle under inner pharynx epithelium is followed by a thin layer of longitudinal muscle fibers.

The anterior intestinal trunk has 6-10 pairs of ramus; each of the posterior trunks shows 12-16 ramus.

The numerous testes are well-developed, large, and oval in shape. Fully sexually mature individuals have 50-60 testes in total, distributed into two longitudinal bands, one on each side of the anterior intestinal trunk (Fig. 2C). The testes extend from the level of the ovaries to the root of the pharynx (Figs 2C, 4A, B). Most testes fill almost completely the dorso-ventral space (Figs 2A, B). The two sperm ducts enlarge to form spermiducal vesicles on either side of the posterior part of the pharynx, which decrease in diameter before penetrating the proximal, anterolateral wall of the penis (Fig. 3A). Within the penis, the sperm ducts run separately for a considerable distance, and then enter into the ejaculatory duct respectively only at the $1 / 3 \mathrm{rd}-1 / 4$ th as long as the penis near the distal portion (Figs 3B-F).

A pair of moderately sized ovaries is situated in the usual ventral space just behind the brain and between the second and third diverticula of the anterior intestinal trunk; it

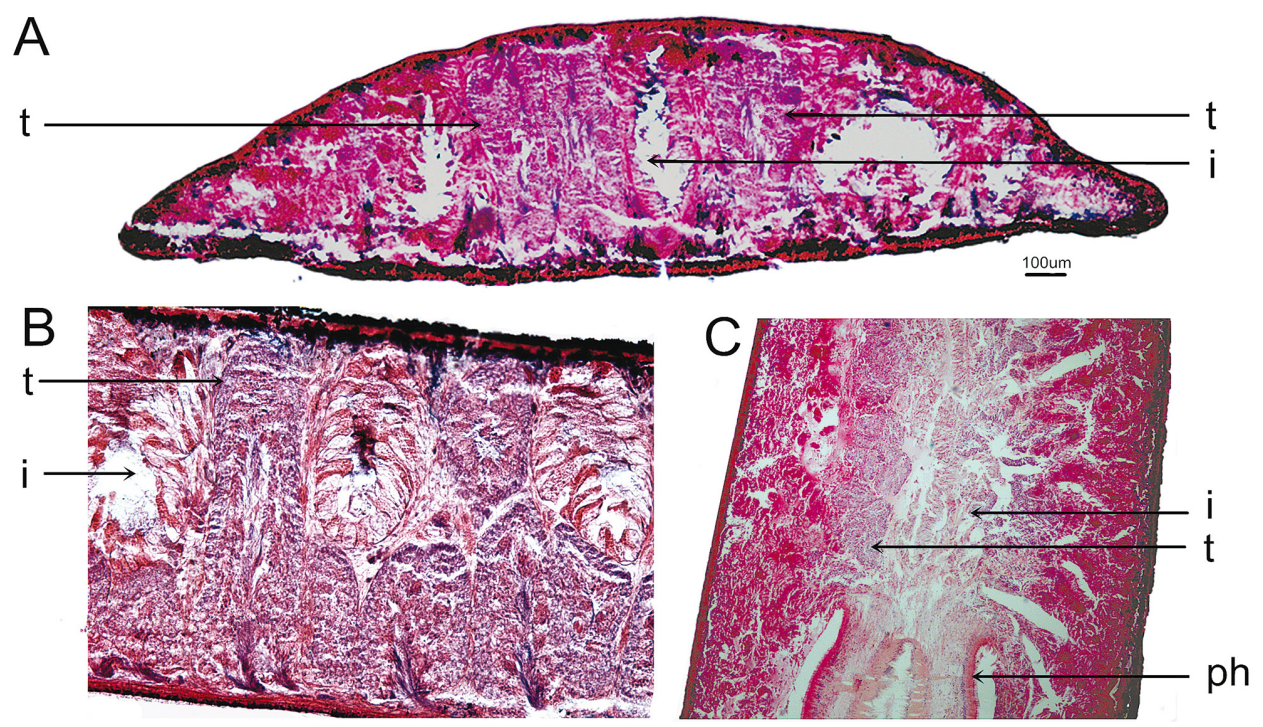

Fig. 2. Photomicrographs showing the testes in different sections of Polycelis yangchengensis: $\mathrm{A}=$ specimen $\mathrm{RB} 7-2$, transverse section, $\mathrm{B}=$ specimen $\mathrm{RB} 2-5$, sagittal section, $\mathrm{A}$ and $\mathrm{B}$ showing the testes filling the dorso-ventral space, $C=$ specimen RB4-3, horizontal section showing the testes extending to the root of the pharynx 


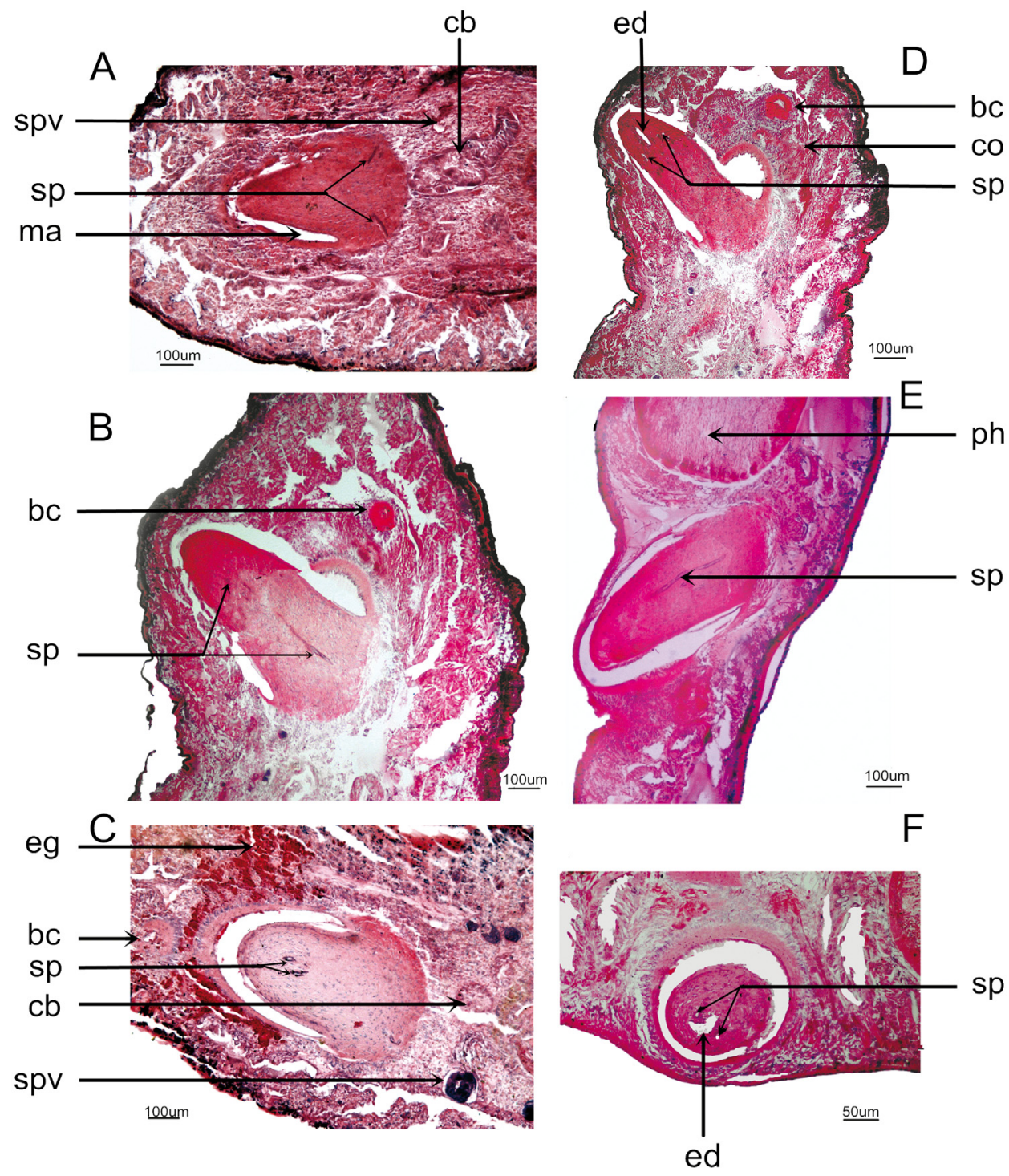

Fig. 3. Photomicrographs showing the two sperm ducts in different sections along the penis of Polycelis yangchengensis: A = specimen CQ5-2, horizontal section showing the entrance of two sperm ducts into the penis, $B=$ specimen RB4-2, horizontal section showing the two sperm ducts along the penis, $C=$ specimen RB5-1, horizontal sections showing two sperm ducts in penis, $\mathrm{D}=$ specimen CQ4-5, horizontal section showing the two sperm ducts and ejaculatory duct in the penis papilla, $\mathrm{E}=$ specimen CQ2-4, sagittal section showing the single sperm duct along the penis, $\mathrm{F}=$ specimen CQ4-9, transverse section showing the two sperm ducts and ejaculatory 
is located at the anterior one-sixth level of the prepharyngeal region and is on the medial side of each ventral nerve cords. The ovaries occupy 1/3rd of the dorso-ventral space of the body (Figs 4A, B). The ovovitelline ducts arise from the terminal ventral wall of the

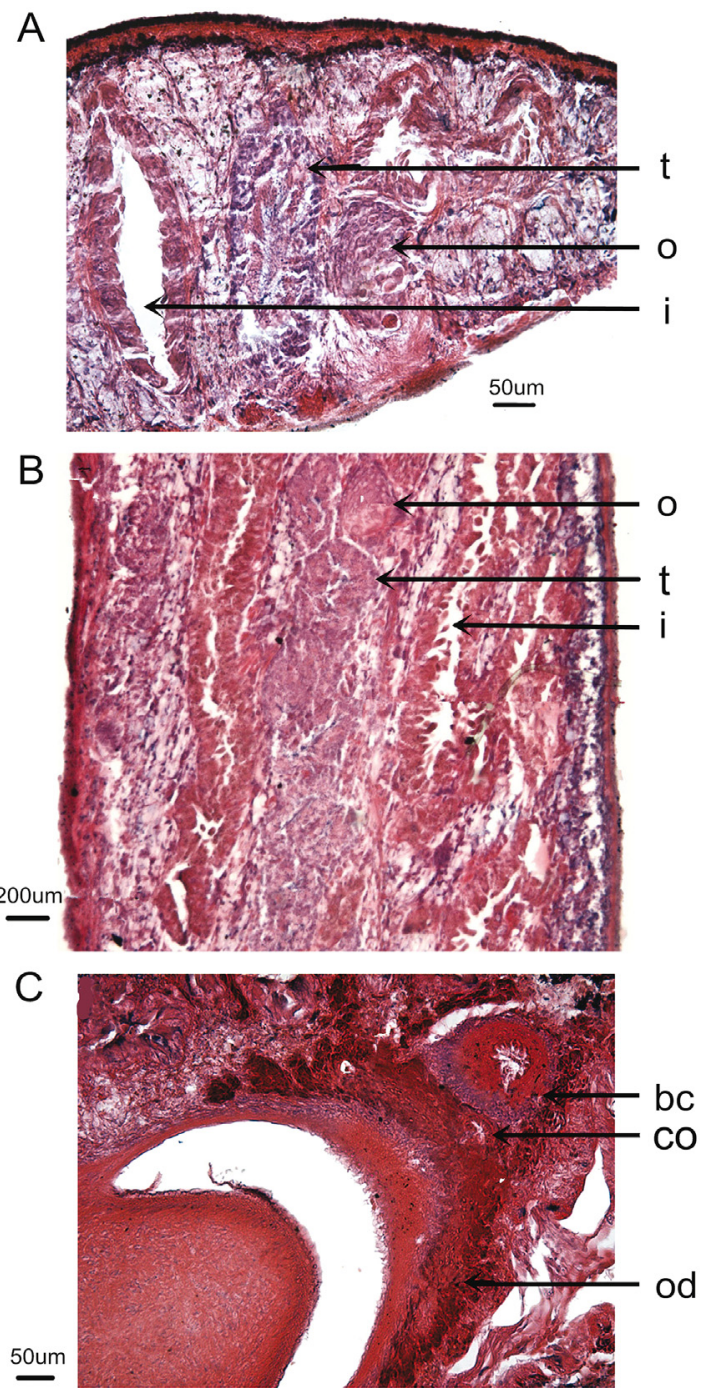

Fig. 4. Photomicrographs showing the ovary and the ovovitelline duct of Polycelis yangchengensis: A = specimen CQ4-2, transverse section showing the ovary and testes, $\mathrm{B}=$ specimen RB3-1, horizontal section showing the ovary and testes. $\mathrm{C}=$ specimen CQ6-4, horizontal section showing the common ovovitelline duct with two ovovitelline ducts ovaries and run ventrally in a caudal direction. At about the level of the genital pore, two ovovitelline ducts ascend on either side of the penis, and then join posterior to the penis to form a common ovovitelline duct which proceeds to common atrium which is close to the junction of the male atrium and the bursal canal and it receives the secretion of many eosinophilic glands (Fig. 4C).

The copulatory bursa is large in size and its shape is somewhat irregular (elongated oval or square), and shorter in the anterior-posterior direction than in the dorso-ventral one (Figs 5, 6A, B). The sac-shaped copulatory bursa is located at the dorso-ventral space between the anterior end of penis and the posterior wall of the pharyngeal cavity; it is lined by a columnar, glandular epithelium bearing basal nuclei and is surrounded by a thick inner circular muscles and a thin outer longitudinal one (Figs 5, 6A, B). Compared to the copulatory bursa, the inner circular muscles of bursal canal is well-developed. The lumen of the proximal part of the bursal canal, close to the bursa, is broad but it becomes narrow dorsally to the male atrium and the penis. From that point onwards, the canal widens again before opening into the common genital atrium. The common atrium is not well developed (Figs 5, 6A, B).

The penis of this species is moderate to large in size and the boundary between the penis bulb and penis papilla is vague and they could not be distinguished. The anterior part (the position of the penis bulb) lacks a distinct cavity in the slides of all specimen examined; the 
posterior part (the position of the penis papilla) has the shape of an elongated cone, and its dorso-ventral lip is symmetrical, the ejaculatory duct is rather wide and opens at tip of penis (Figs 5, 6A-C). The musculature of the penis is well-developed, consisting of a very thick layer of inner circular fibers and a thin layer of outer longitudinal one (Figs 5, 6D).

Karyology - We examined 100 well-dispersed metaphase plates of Polycelis yangchengensis. In 69.82 . \% of the metaphase plates the chromosome number was $2 n=38$. Karyotype parameters, including the relative length, arm ratio, and centromere index, are given in Table 1. A chromosomal plate and the idiogram of the karyotype are shown in Figs 7A, B and C. The results indicate that the karyotype of Polycelis yangchengensis shows a diploid number of 38, with a karyotype formula of $2 \mathrm{n}=38=24 \mathrm{~m}+14 \mathrm{sm}$, in which Nos 6, 9, 10, 13, 14, 16 and 19 are submetacentric and the others are metacentric. The first pair of chromosomes is clearly larger than the other pairs being 5.37 times as large as the smallest chromosome.

Distribution and ecology - This species is distributed above alt. $1100 \mathrm{~m}$ and shows the obvious vertical distribution (Figs 8A, B). They were found together with Dugesia species at about alt. $1000 \mathrm{~m}$, the Dugesia species are distributed below alt. $1000 \mathrm{~m}$ in the same mountain. Up to the present, we have not observed freshly regenerated anterior or posterior ends both in the locality and the laboratory culture, so, we presume that this species reproduces only sexually. Its breeding season is usually from autumn to the next spring (October to February of next year). The newly laid cocoons are red-brown (Fig. 8C), and then turn brownish dark after 2 to 3 days, they hatch about 70-110 days

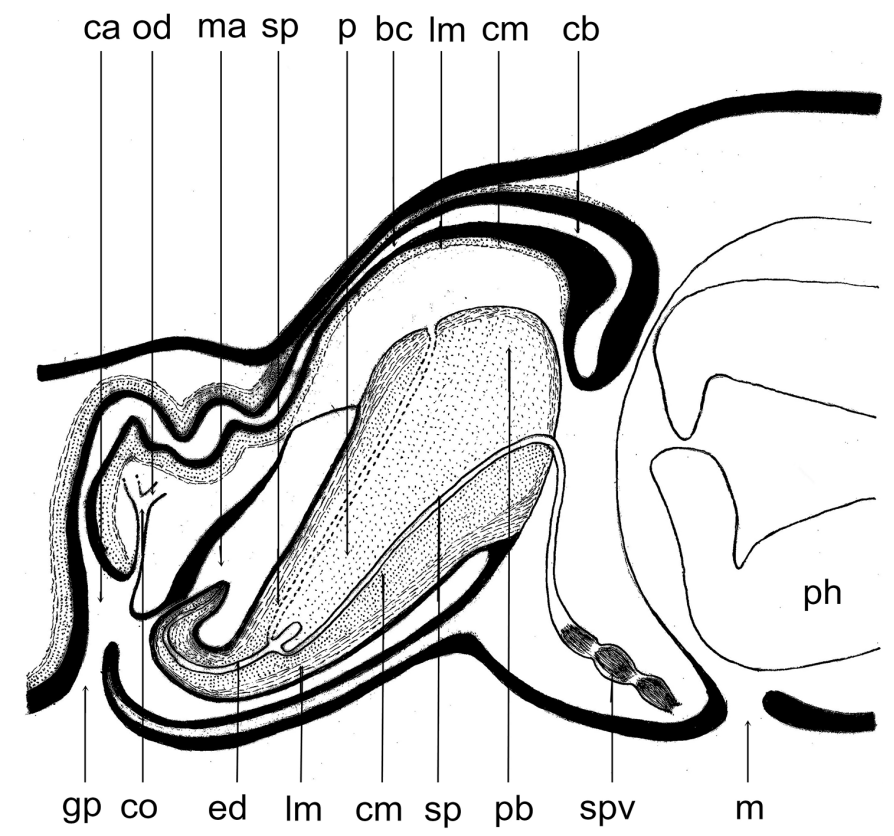

Fig. 5. Polycelis yangchengensis: Holotype CQ1, sagittal reconstruction of the copulatory apparatus (anterior to the right) 
Table 1. Karyotype parameters of Polycelis yangchengensis.

\begin{tabular}{ccccc}
\hline $\begin{array}{c}\text { No. of } \\
\text { chromosome }\end{array}$ & Relative length & Arm ratio & $\begin{array}{c}\text { Centromere } \\
\text { index }\end{array}$ & $\begin{array}{c}\text { Chromosome } \\
\text { type }\end{array}$ \\
\hline 1 & $15.14 \pm 0.54$ & $1.04 \pm 0.014$ & $48.93 \pm 0.35$ & $\mathrm{~m}$ \\
2 & $7.29 \pm 0.03$ & $1.29 \pm 0.016$ & $43.85 \pm 0.29$ & $\mathrm{~m}$ \\
3 & $6.71 \pm 0.59$ & $1.52 \pm 0.011$ & $39.81 \pm 1.82$ & $\mathrm{~m}$ \\
4 & $5.55 \pm 0.14$ & $1.26 \pm 0.025$ & $44.56 \pm 0.47$ & $\mathrm{~m}$ \\
5 & $5.25 \pm 0.09$ & $1.36 \pm 0.011$ & $42.53 \pm 0.21$ & $\mathrm{~m}$ \\
6 & $5.20 \pm 0.16$ & $2.22 \pm 0.06$ & $31.82 \pm 0.57$ & $\mathrm{sm}$ \\
7 & $5.11 \pm 0.01$ & $1.52 \pm 0.03$ & $40.01 \pm 0.45$ & $\mathrm{~m}$ \\
8 & $4.98 \pm 0.02$ & $1.66 \pm 0.03$ & $37.92 \pm 0.46$ & $\mathrm{~m}$ \\
9 & $4.93 \pm 0.05$ & $2.38 \pm 0.06$ & $30.25 \pm 0.58$ & $\mathrm{sm}$ \\
10 & $4.71 \pm 0.12$ & $1.75 \pm 0.02$ & $36.48 \pm 0.31$ & $\mathrm{sm}$ \\
11 & $4.59 \pm 0.20$ & $1.20 \pm 0.01$ & $45.45 \pm 0.21$ & $\mathrm{~m}$ \\
12 & $4.47 \pm 0.26$ & $1.33 \pm 0.016$ & $43.08 \pm 0.31$ & $\mathrm{~m}$ \\
13 & $4.41 \pm 0.19$ & $2.64 \pm 0.03$ & $27.63 \pm 0.24$ & $\mathrm{sm}$ \\
14 & $4.15 \pm 0.08$ & $1.92 \pm 0.02$ & $34.36 \pm 0.27$ & $\mathrm{sm}$ \\
15 & $4.14 \pm 0.18$ & $1.32 \pm 0.012$ & $43.23 \pm 0.22$ & $\mathrm{~m}$ \\
16 & $3.73 \pm 0.02$ & $2.18 \pm 0.013$ & $31.45 \pm 1.91$ & $\mathrm{sm}$ \\
17 & $3.48 \pm 0.12$ & $1.36 \pm 0.08$ & $42.44 \pm 1.62$ & $\mathrm{~m}$ \\
18 & $3.32 \pm 0.20$ & $1.47 \pm 0.017$ & $40.52 \pm 0.29$ & $\mathrm{~m}$ \\
19 & $2.82 \pm 0.05$ & $1.79 \pm 0.016$ & $35.94 \pm 0.22$ & $\mathrm{sm}$ \\
\hline
\end{tabular}

$\pm:$ Mean values and standard deviation

after laying at $4^{\circ} \mathrm{C}$ in the laboratory and 50-80 days in the field locations, 4 to 6 juveniles emerge from one cocoon and they are 3-5 mm long and 0.6-1.0 $\mathrm{mm}$ wide. The cocoon is spherical in shape $(2-2.5 \mathrm{~mm}$ in diameter) and without a stalk, the new juvenile planarians are white and translucent, they attain the color of mature specimens in the course of the first month (Fig. 8C).

\section{DISCUSSION}

Polycelis yangchengensis belongs to the genus Polycelis based on the characteristics of the genital anatomy, histology, and morphology. According to the Kenk's new taxonomic system of the genus (Kenk 1953, 1974, KawaKatsu \& Mrtchell 1998), the new species lacked adenodactyls and excessive development of the muscle coat of the male genital artrum; moreover, the new species is different from the species belonging to the genus Ijimia, which possessed solid adenodactyls and distributed only in Europe. 


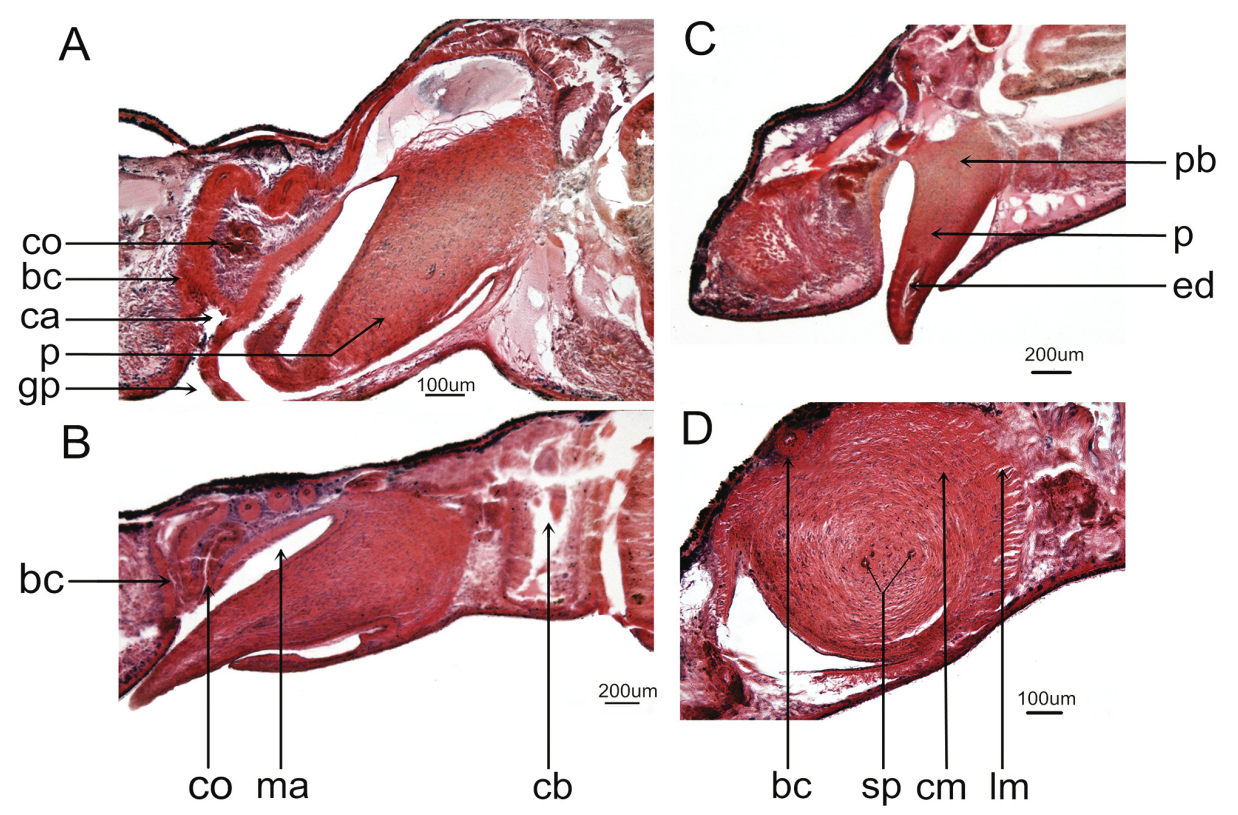

Fig. 6. Photomicrographs showing the copulatory apparatus in different sections of Polycelis yangchengensis: A = holotype CQ1-1, sagittal section showing the bursal canal and copulatory bursa and the penis, $\mathrm{B}=$ specimen RB2-4, sagittal section showing the penis and the bursal canal and common ovovitelline duct and the male atrium, C = specimen RB1-2, sagittal section showing the penis bulb and the penis papilla and the ejaculatory duct, $\mathrm{D}=$ specimen RB7-4, transverse section showing the musculature of the penis

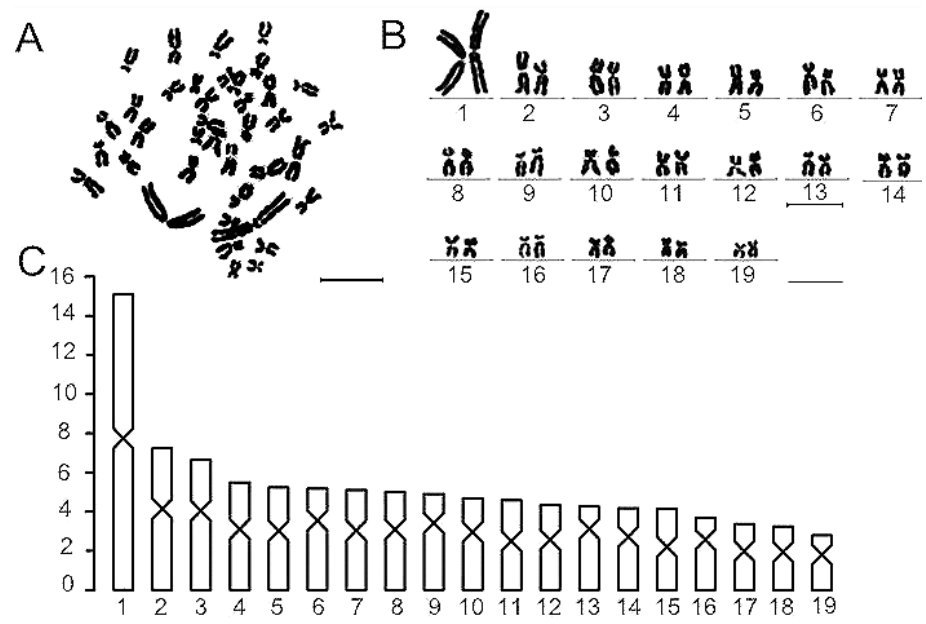

Fig. 7. Polycelis yangchengensis: $\mathrm{A}=$ metaphasic plate, $\mathrm{B}=$ karyogram, $\mathrm{C}=$ ideogram, Chromosome number: $2 n=38$, karyotype formula, $2 n=38=24 m+14 \mathrm{sm}$, in which Nos 6, 9, 10,

$13,14,16$ and 19 are submetacentric and the others are metacentric. Scale bar: $5 \mu \mathrm{m}$ 
The new species differs from its congeners in its morphology, the anatomical features of the reproductive organs and the karyotype. In particular, it is characterized by (1) most of testes, which are well-developed, occupying the entire dorso-ventral space and extending from the level of the ovaries; (2) a elongated conical penis with well-developed inner circular fibers and a thin layer of outer longitudinal one; (3) absence of an intrabulbar seminal vesicle or bulbar cavity and the boundary between penis bulb and penis papilla vague; (4) two sperm ducts separately entering into the ejaculatory duct; (5) bursal canal surrounded by a well-developed coat of circular muscles; (6) karyotype formula is $2 \mathrm{n}=38=24 \mathrm{~m}+14 \mathrm{sm}$.

Almost in all known species of Polycelis the penis is composed of penis bulb and penis papilla, and the penis bulb is characterized by a large or small bulbar cavity and the two sperm ducts open into the bulbar cavity separately.
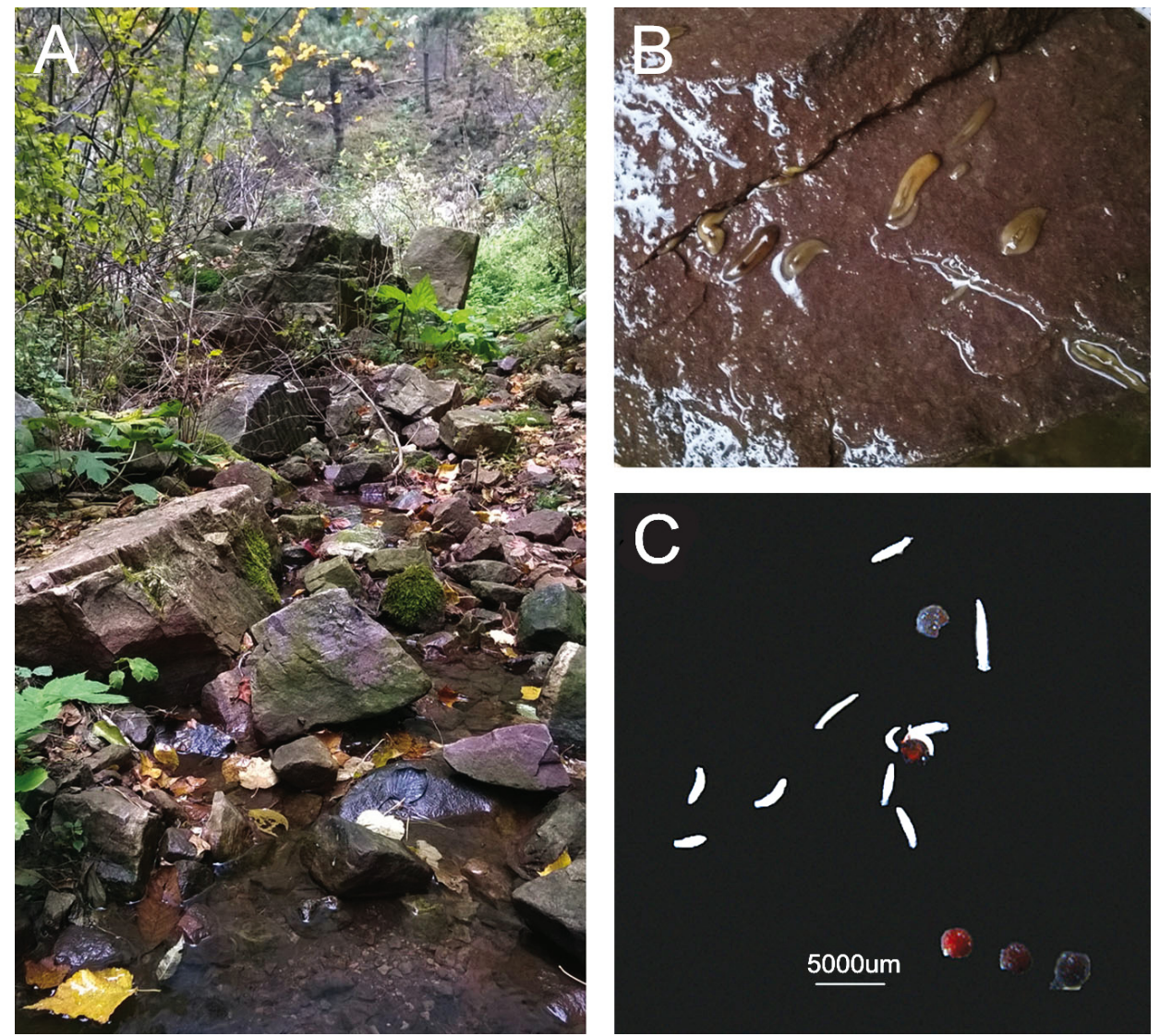

Fig. 8. Photographs showing the locality, the juveniles and the cocoons. $\mathrm{A}=$ Chengqianggen locality of Taihang Mountains, B = the worms under the stone in the locality, $\mathrm{C}=$ the new juvenile planarians and the cocoons 
For instance, among specimens from diverse localities of the common northern Japanese species Polycelis sapporo Ijima et Kaburaki, 1916, most have a large bulb which contains a very wide bulbar cavity, however, precious few specimens have a rather narrow bulbar cavity (KAWAKATsu et al. 1974). The species Polycelis remota Smith, 1988, distributed in eastern North America, also has a large bulbar cavity (Sмiтн 1988). Whereas the new species lacks a distinct bulbar cavity and the two sperm ducts directly enter into the ejaculatory duct, at the same time, the boundary between penis bulb and penis papilla is vague, we cannot clearly distinguish the two parts.

Altogether eight species of Polycelis from China have been reported up to now, among them, a large intra-bulbar cavity has also been reported for the following species: P. nyingchica and P. xigazensis (Liv 1994); P. wutaishanica, P. jinglensis and P. jingyuanica (Liv 1996). The new species resembles to P. lhnzhuica and $P$. jingyuanica in appearance including the number of eyes and the body color. However, P. lhnzhuica has an oval penis and a small bulbar cavity, while $P$. jingyuanica has a thick and long penis and a large oval bulbar cavity (Liu 1995), in contrast to the new species. Regarding anatomical characteristics of the genital apparatus, the new species is similar to $P$. sinensis. There are some differences in the inner structure of penis, number of eyes and testes; $P$. sinensis is provided with $150-170$ eyespots and $80-100$ testes and a small bulbar cavity in contrast to the situation in $P$. yanchengensis.

Compared to all the known species in Polycelis, $P$. yangchengensis is most similar to Polycelis kashmirica Hyman, 1934 with respect to size, body color and copulatory organs (Liv 1993). However, there are also some crucial features that are different from $P$. kashmirica, which was collected in Kashmir by an exploring expedition of Yale, USA, in 1932. It was named first Polycelis tibetica Hyman, 1934 and later renamed Polycelis kashmirica by Liu (1993). The penis of $P$. kashmirica may be retracted or considerably extended. When the penis retracts, the penis bulb is obvious and houses a spacious cavity, while the penis papilla appears as a short cone. However, when the penis extends, the penis bulb contracts, and a muscular block is formed at the base of penis and the bulbar cavity is compressed, but its boundary between penis bulb and penis papilla can still be recognized because of the presence of the two small papillae on which the sperm ducts end. In the latter situation, the penis papilla becomes a long cone. Although this condition with extended penis in $P$. kashmirica resembles that of $P$. yangchengensis, the bulbar cavity is not observed in any of our individuals that were sectioned in the present study. In addition, the boundary between penis bulb and penis papilla is vague in all histological sections of the new species because it does not have small papillae, all of these features are different from those of $P$. kashmirica. Furthermore, the prepharyngeal testes of $P$. kashmirica are ventral, whereas most of the follicles in the new species occupy the entire dorso-ventral space and they extend 
from the level of the ovaries rather than from the posterior level of the ovaries, this is differs from its congeners.

Concerning the ecology and habitat, the new species occurs only in the upper streams. At present, our field data indicate that the specimens, collected from Taihang Mountains, China, show typical patterns of vertical distribution, the Polycelis species are usually restricted the high-altitude area of the mountains (above alt. $1100 \mathrm{~m}$ ) and in the chemically clean waters, the range of water temperatures tolerated is $1-14^{\circ} \mathrm{C}$, the animals are very sensitive to the temperature fluctuations, when they are removed from the spring and taken to the laboratory, some animals usually disintegrated. At middle-altitude area of the mountains (alt. 1000-1100 m), the Polycelis species and Dugesia species are usually co-occur. At low-altitude area of the mountains (below alt. $1000 \mathrm{~m}$ ), there are only Dugesia species. In a word, the currently known distributions of Chinese Polycelis species are all found in cold spring water of high-altitude areas of the mountains, but not in lower mountains or plains. The habitat of the new species is very similar to those of Polycelis coronate Girard, 1891 (from America), P. pamirensis de Beaucham, 1959 (from Afghanistan) and P. kashmirica, which also live in mountain streams and springs (Hyman 1931, 1934, IcHIKAWA \& KAWAKATSU 1962). In contrast to some species, such as, $P$. sapporo (from Japan), P. remota (from America) and P. nigra Müller, 1774 (from Europe), distributed in the lowland, hilly and low mountainous regions (KAwAKATsu et al. 1974). Moreover, the cocoon of the new species is medium sized. In general, the cocoon sizes of marine and freshwater triclads are known to depend on the sizes of the worms (Zaitseva et al. 2006, Vreys \& Michiels 1995). For instance, Baikalobia variegate Korotneff, 1912, 25-28 mm long and 12-13 mm wide worm, lay cocoons 3.3-4.5 mm in diameter. Another smaller species, Archicotylus stringulatus Korotneff, 1912, 4-6 mm long and $1.5 \mathrm{~mm}$ wide, lays cocoons of less than $1 \mathrm{~mm}$ in diameter. The number of juveniles emerging from one cocoon varies in each species, for example it is 1-15 specimens in Dugesia japonica Ichikawa et Kawakatsu, 1964 and 2-14 specimens are hatched from the cocoons of Baikalobia genus (IchiKawa \& KawaKatsu 1962, KawaKatsu 1974). The number of juvenile specimens representing Polycelis genera that emerge from one cocoon of average size varies from 8 to 21 (KAWAKATSU 1974, YAMADA 1984), in comparison, the number of juvenile worms of the new species is fewer (only 4-6). This may be caused by unsuspected environmental factors.

As for karyology, chromosome number and karyotype of Polycelis species are rarely reported. $P$. yangchengensis shows a diploid chromosome complement of 38 chromosomes with basic number $n=19$. According to the ratio of chromosome length and arm ratio based on the classification criterion of $\mathrm{LI}$ (1985) (Table 2), the karyotype of $P$. yangchengensis belongs to type 2C, which is an asymmetric karyotype. Chromosomal number and karyotype of $P$. yangchengensis are different from those of other Polycelis species known thus far, such as 
P. wutaishanica, $P$. sapporo and $P$. kashmirica, the chromosomal number of which is $2 \mathrm{n}=42$ (Chen et al. 2008, Teshirogi et al. 1978). Further, the chromosome number of Polycelis felina Dalyell, 1814 is $2 \mathrm{n}=18$ (Kalafatic et al. 2004).

Chromosomal polymorphism exists widely in planarians. For example, Polycelis nigra, P. tenuis Ijima, 1884, and P. felina have been reported to show chromosomal polymorphism, including polyploids and aneuploids, which might be related to differences in their habitats (Teshirogi et al. 1978, 1979). The karyology results of $P$. yangchengensis collected from different seasons, up till now show no evidence for polymorphism, perhaps because the specimens are from the same locality. However, more precise information on chromosomes of Polycelis planarians is required to understand their intra- and interspecific variations. This could be accomplished using more sensitive techniques, such as chromosome banding, fluorescent staining or in situ hybridization, to obtain more data for taxonomy.

Acknowledgements - We are grateful to Jiuquan Lv, Hongxing Niu and Xiangfu Yang for collection of the specimens. We are indebted to an anonymous reviewer for re-organizing and re-writing an earlier version of the manuscript. This work was supported by grants from the National Natural Science Foundation of China (Nos. 31570376, 31471965, 31170357), the Ph.D. Programs Foundation of the Ministry of Education of China (No. 200804760003).

\section{REFERENCES}

Chen, G. W., Chen, X. H. \& Liu, D. Z. (2001a): Advances in the study of Turbellaria in China. - Acta Hydrobiologica Sinica 25(4): 406-412.

Chen, G. W., Lv, J. Q., MA, J. Y. \& Liv, D. Z. (2001b): Report on freshwater planarians from China. - Acta Zoologica Sinica 47(Suppl): 9-12.

Chen, G. W., Xue, D. M., Sun, X. J. \& Liu, D. Z. (2005): The microscopical observation on the testis tissue construction of the Polycelis planarians from Yushu in Qinghai province. - Journal of Henan Normal University 33(2): 145-147.

Chen, G. W., Wang, Y. L., Wang, H. K., Fu, R. M., Zhang, J. F. \& Liu, D. Z. (2008): Chromosome and karyotype analysis of Polycelis wutaishanica (Turbellaria, Tricladida) from Shanxi province, China. - Acta Zootaxonomica Sinica 33(3): 449-452.

Hyman, L. H. (1931): Studies on the morphology, taxonomy, and distribution of North American triclad Turbellaria. - Transactions of the American Microscopical Society 50: 124-135. https://doi.org/10.2307/3222281

Hyman, L. H. (1934): Report on Triclad Turbellaria from Indian Tibet. - Memoirs of the Connecticut Academy of Arts and Sciences 10: 5-16.

Ichikawa, A. \& Kawakatsu, M. (1962): Report on freshwater Planaria from Afghanistan. - XIVth Annual Meeting of the Hokkaido Branch of the Zoological Society of Japan, pp. 175-187.

Kalafatic, M., Kopjar, N., Zrna, G., Zupan, I., Kovacevic, G. \& Franjevic, D. (2004): Karyological analysis of two allopatric populations of planarian Polycelis felina in Croatia. - Folia Biologica 52: 131-133. 
KAwAKATSU, M. (1974): Further studies on the vertical distribution of freshwater planarians in the Japanese Islands. Pp. 291-338. - In: Riser, N. W. \& Hyman, L. H. (eds): The HYMAN Memorial Volume, Biology of the Turbellaria. McGraw-Hill Book Co. New York.

Kawakatsu, M. \& Mitchell, R W. (1998): Redescription of a North America freshwater planarian, Seidlia remota (Smith, 1988), with taxonomic notes on seidlia and polycelis species from the Far East and central Asia (Turbellaria, seriata, tricladida, paludicola). - Bulletin of Fuji Women's College 36: 95-110.

Kawakatsu, M., Yanagita, Y., Teshirogi, W. \& Ichikawa, A. (1974): Studies on the taxonomy and morphology of the Japanese freshwater Planarian Polycelis sapporo. Annotationes Zoologicae Japonenses 47: 239-260.

Kenk, R. (1953) The fresh-water Triclads (Turbellaria) of Alaska. - Proceedings of the United States National Museum 103: 163-186. https://doi.org/10.5479/si.00963801.103-3322.163

KENK, R. (1974): Index to the genera and species of the freshwater triclads (Turbellaria) of the World. - Smithsonian Contributions to Zoology 183: 1-90. https://doi.org/10.5479/ si.00810282.183

Levan, A., Fredga, K. \& Sandberg, A. A. (1964): Nomenclature for centromeric position on chromosomes. - Hereditas 52: 201-220. https://doi.org/10.1111/j.1601-5223.1964.tb01953.x

Lıu, D. Z. (1993): Chinese freshwater turbellarians. - Beijing Normal Univ. Press, Beijing, 184 pp.

LiU, D. Z. (1994): Notes on two new species of the genus Polycelis from Xizang Autonomous Region, China (Tricladida: Paludicola: Planariidae). Acta Zootaxonomica Sinica 19(1): 10-15.

Liv, D. Z. (1995): Notes on two new species of the genus Polycelis from China (Tricladida: Paludicola: Planariidae). - Acta Hydrobiologica Sinica 19(2): 152-156.

Liv, D. Z. (1996): Notes on four new species of the genus Polycelis from China (Tricladida: Paludicola: Planariidae). Acta Zootaxonomica Sinica 21(4): 389-398.

Li, M. X. \& Chen, R. Y. (1985): The problem on karyotypic standardization in plants. - Wuhan Botany Research 3(4): 297-302.

Sмiтh, D. G. (1988): A new, disjunct species of triclad flatworm (Turbellaria: Tricladida) from spring in southern New England. - The Biological Bulletin 157: 246-252. https:// doi.org/10.2307/1541565

Teshirogi, W., Hasebe, K. \& Ishida, S. (1979): Karyological studies of the freshwater planarian genus Polycelis. - Zoological Magazine 88: 664.

Teshirogi, W., Nimmura, F., IshidA, S. \& Hasebe, K. (1978): Karyotypes of some freshwater planarians and chromosomal variation in neoblasts of regenerating pieces. - Zoological Magazine 87: 535.

Vreys, C. \& Michiels, N. (1995): The influence of body size on immediate reproductive success in Dugesia gonocephala (Tricladida, Paludicola). - Hydrobiologia 305: 113-117. https://doi.org/10.1007/978-94-011-0045-8_18

YAMADA, T. (1984): Devising a new apparatus for long-period culture of freshwater planarians, with special reference to the life-history of Japanese three species. Biology of Inland Waters 3: 28-38.

Zaitseva, E. P., Mizandrontsev, I. B. \& Timoshin, O. A. (2006): Postembryonic development and growth dynamics of Baikaiobia guttata (Gerstfeldt, 1858) (Plathelminthes): first report on the life cycle of endemic Tricladida from Lake Baikal. - Hydrobiologia 568: 239-245. https://doi.org/10.1007/s10750-006-0308-8

Received February 1, 2016, accepted January 6, 2017, published July 21, 2017 